\title{
Biological Markers for Alcohol Withdrawal Seizures: A Retrospective Analysis
}

\author{
Deniz Karagülle $^{a} \quad$ Annemarie Heberlein ${ }^{a} \quad J u l i a$ Wilhelm ${ }^{a} \quad H_{\text {Helge Frieling }}{ }^{a}$ \\ Johannes Kornhuber $^{\mathrm{b}}$ Stefan Bleich ${ }^{\mathrm{a}}$ Thomas Hillemacher $^{\mathrm{a}}$ \\ ${ }^{a}$ Center for Addiction Research, Department of Psychiatry, Social Psychiatry and Psychotherapy, Hannover Medical \\ School, Hannover, and ${ }^{b}$ Department of Psychiatry and Psychotherapy, University Hospital Erlangen, Erlangen, \\ Germany
}

\section{Key Words}

Alcohol withdrawal · Seizures $\cdot$ Homocysteine $\cdot$

Carbohydrate-deficient transferrin • Prolactin •

Detoxification $\cdot$ Dependence $\cdot$ Alcoholism

\begin{abstract}
Aims: Alcohol withdrawal seizures (AWS) are among the most important possible complications during the detoxification treatment of alcohol-dependent patients. Pharmacological therapy is often used during detoxification, but can cause dangerous side effects [Eur Addict Res 2010;16:179184]. In separate studies several biological markers have been described as being associated with AWS risk. We investigated the role of homocysteine (HCT), carbohydrate-deficient transferrin (CDT) and prolactin (PRL) as biological markers for the risk of developing AWS. Methods: The present study included 189 alcohol-dependent patients of whom 51 had a history of AWS. We investigated the HCT, CDT and PRL levels of all patients and calculated sensitivity and specificity. Bayes' theorem was used to calculate positive (PPV) and negative (NPV) predictive values. Results: The highest combined sensitivity and specificity for \%CDT was reached at a plasma cutoff value of $3.75 \%$. The combination of HCT at a cutoff value of $23.9 \mu \mathrm{mol} / \mathrm{l}$ and \%CDT at a cutoff value of
\end{abstract}

3.75\% showed the best predictive values (sensitivity $47.1 \%$, specificity $88.4 \%$, PPV 0.504, NPV 0.870). Conclusion: A combined assessment of HCT and CDT levels can be a useful method to identify patients at a higher risk of AWS, which may lead to a more individualized therapy.

Copyright $\odot 2012$ S. Karger AG, Basel

\section{Introduction}

Alcohol abuse and dependency represent a high risk for health [1] and an avoidable cost for society [2]. Therapeutic options, especially with regard to detoxification, play an important role. Alcohol withdrawal seizures (AWS) are among the most important possible complications of alcohol detoxification. To prevent AWS and other possible complications like delirium tremens several medication schemes are in use during detoxification. However, pharmacological therapy can be associated with side effects like hyponatremia, thrombopenia and allergic reactions [3]. Predictors for individual risks of withdrawal seizures during alcohol detoxification could open the way for an individualized pharmaceutical therapy or for a more intensive care of the detected patients.

\section{KARGER}

Fax +41613061234 E-Mail karger@karger.ch www.karger.com
(C) 2012 S. Karger AG, Basel

$1022-6877 / 12 / 0183-0097 \$ 38.00 / 0$

Accessible online at:

www.karger.com/ear
Deniz Karagülle

Center for Addiction Research (CARe), Department of Psychiatry

Social Psychiatry and Psychotherapy, Hannover Medical School

Carl-Neuberg-Strasse 1, DE-30625 Hannover (Germany)

Tel.+49511532 4156,E-Mail karaguelle.deniz@mh-hannover.de 
The pathophysiological mechanisms of the development of AWS are not completely clarified. There is evidence that homocysteine (HCT) is elevated in nonabstinent alcoholics and decreases during alcohol withdrawal $[4,5]$. It is shown that a higher HCT blood level is suitable to predict first-onset AWS [6] and is also correlated with previous withdrawal seizures [7]. In recent years different cutoff values for HCT plasma levels were specified. The most common fasting plasma level of HCT averages between 5 and $15 \mu \mathrm{mol} / \mathrm{l}$. A HCT level between 4.9 and $11.7 \mu \mathrm{mol} / \mathrm{l}$ seems to be an adequate interval in populations without a nutritional deficit [8], but the convenience of these cutoff levels is low for an assessment of AWS risk. In alcohol-dependent patients the HCT levels are highly elevated. Bleich et al. [9] showed that the highest combined sensitivity and specificity to predict the occurrence of first-onset AWS is calculated at a HCT plasma level of $23.9 \mu \mathrm{mol} / \mathrm{l}$.

Carbohydrate-deficient transferrin (CDT) has been proposed as the most specific biomarker of chronic alcohol misuse [10] and probably reflects, at least partially, the severity of alcohol dependence. Hence, CDT was discussed as a possible biomarker to detect patients with higher risk of AWS. In an investigation to confirm \%CDT as a predictive parameter for AWS, the best predictive validity was calculated at a cutoff value of $5.4 \%$, but the authors pointed out that CDT alone is not suitable as a predictor for individual withdrawal seizure risk [11].

Regarding prolactin (PRL), there is clinical evidence that PRL levels increase following acute and chronic ethanol exposure [12-14] and decrease in abstinent patients $[15,16]$. Also, as recent study results indicate, PRL serum levels seem to be associated with the severity of alcohol dependence and withdrawal symptoms [17]. PRL is supposed to be associated with the dopaminergic system. This supposable association would associate the tuberoinfundibular with the mesocorticolimbic dopamine system. Both systems are regulated by $\mathrm{D}_{2}$ receptors. There seems to be an association between these receptors and the affective and cognitive functions [18], PRL secretion and the activity of the tuberoinfundibular dopamine neurons [19]. Dopamine inhibits the release of PRL in the hypothalamus [20]. Long-term alcohol consumption leads to a chronic stimulation of dopaminergic receptors $[21,22]$.

Other investigations showed that PRL can act as a predictive value for the increased risk of seizures during alcohol withdrawal. However, a combined assessment of PRL and HCT did not lead to clear better predictive values compared to the predicting HCT alone $[23,24]$.
The aims of our study were to investigate (1) whether HCT, CDT and PRL may act as biological markers to appraise the individual risk of AWS, and (2) whether the combined assessment of different parameters may lead to better results.

\section{Subjects and Methods}

This study is part of the Franconian Alcoholism Research Studies, a large prospective research study [4]. Approval of the local ethical committee of the University of Erlangen-Nuremberg, in accordance with the ethical standards of the 1964 declaration of Helsinki, was obtained. Written informed consent was obtained from all patients. The same patient sample has been used in other previously published studies focusing on an association between PRL, HCT and previous AWS [7, 9, 23, 24]. All 189 (153 male, 36 female) alcohol-dependent patients fulfilled the criteria of alcohol dependency according to the International Classification of Diseases (ICD-10). The inclusion to the study occurred on the day of admission to the detoxification unit. All patients were treated with clomethiazole and carbamazepine during detoxification, hence none of the patients suffered from AWS during the study period. Therefore, we used the history of AWS to assess the risk of seizures as previously described [7, 23, 25]. Patients with concomitant psychiatric disorder, other substance abuse apart from alcohol and nicotine or common risk factors for hyperhomocysteinemia, like altered nutritional status or endocrinological problems, were not included in the study. Further exclusion criteria were neurological disorders like epilepsy, known risk factors for the development of withdrawal seizures, such as cerebral diseases or lesions and relevant neurological deficits, liver cirrhosis, and renal or pancreatic dysfunction. Patients did not receive any medication (i.e. antipsychotics, vitamin substitution supplements) that can affect the plasma level of HCT.

Blood samples were taken at admission before pharmacological detoxification was started. We analyzed HCT (Axis ${ }^{\circledR}$ Homocysteine EIA/Oslo, Norway, IBL-No. AX 513 01), CDT (\%CDT turbidimetric immunoassay, reference value $<2.6 \%$, Axis-Shield ${ }^{\circledR}$, Norway) and PRL (microparticle enzyme immunoassay, reference value: males $<18 \mathrm{ng} / \mathrm{ml}$, Abbott AxSYM, cat. \# 7A62-22, Abbott Park, Ill., USA).

Statistical Analysis

All parameters followed a standard distribution according to the Kolmogorov-Smirnov test.

Group comparisons between patients with versus without a history of seizure were performed by t tests. PRL, HCT and \%CDT serum levels were fed into logistic regression analysis (ENTER method) to determine if independent predictive properties existed. Only parameters showing a trend $(\mathrm{p}<0.1)$ towards significant prediction in the logistic regression of all three parameters were used for further analysis.

A receiver operator characteristics (ROC) curve and the area under the curve (AUC) were used to measure the effectiveness of the different markers. The combination of markers was calculated after standardization to a mean of 0 and SD of 1 (z-transformed). The $\mathrm{z}$-transformation was necessary to adapt the weighting of the 
variables. AUCs were calculated and comparisons were made between markers and their combination, using DeLong's method. The standard method for AUC confidence intervals was applied. Comparisons of one biomarker or cluster between the female and male subgroup were made using the following statistic:

$$
\mathrm{Z}=\left(\mathrm{AUC}_{\mathrm{M}}-\mathrm{AUC} \mathrm{C}_{\mathrm{F}}\right) / \sqrt{\mathrm{SE}_{\mathrm{M}}^{2}+\mathrm{SE}_{\mathrm{F}}^{2}},
$$

where $\mathrm{AUC}_{\mathrm{M}} / \mathrm{AUC}_{\mathrm{F}}=$ area under the curve for male/female subgroup and $\mathrm{SE}_{\mathrm{M}} / \mathrm{SE}_{\mathrm{F}}=$ standard error of the $\mathrm{AUC}$, which was compared with the standard normal distribution.

A cutoff value for \%CDT was calculated as the value with the highest combined sensitivity and specificity (Youden's index). The previously published cutoff value for HCT fixed at $23.9 \mu \mathrm{mol} / \mathrm{l}$ was used [9].

Sensitivity and specificity were calculated for all biomarkers using these cutoff values.

The positive likelihood ratio $(\mathrm{LR}+)$ was calculated as the sensitivity/(1 - specificity). 95\% CIs for sensitivity, specificity and positive predictive values (PPV) were calculated using Wilson's method. $\mathrm{p}$ values $<0.05$ (two-sided) were considered statistically significant. All calculations were made for male and female patients separately to study gender differences. To formally test for an interaction between gender and HCT/CDT or the seizure scores, multinomial logistic regression using a saturated model were calculated. Data were analyzed employing PASW ${ }^{\mathrm{TM}}$ for Windows 17.0 (SPSS Inc., Chicago, Ill, USA) and Analyse-it ${ }^{\mathrm{TM}}$ (Analyse-it ${ }^{\mathrm{TM}}$ Software, Leeds, UK).

\section{Results}

Table 1 shows the demographic characteristics of the study population.

189 patients were included in the study (153 male, 36 female). 51 had suffered AWS (44 male, 7 female) in the past. Patients with a history of AWS had significantly higher \%CDT und HCT levels (CDT, seizure vs. no seizure: $6.71 \pm 4.19$ vs. $5.36 \pm 3.31$, t test $=-2.073$, d.f. $=74$, $\mathrm{p}=0.042$ and HCT, seizure vs. no seizure: $32.56 \pm 26.20$ vs. $19.54 \pm 9.97$, $\mathrm{t}$ test $=-3.460$; d.f. $=55, \mathrm{p}=0.001)$ and showed a trend towards higher PRL levels (seizure vs. no seizure: $16.79 \pm 11.46$ vs. $13.09 \pm 7.61$, t test $=-1.869$, d.f. $=50.961, \mathrm{p}=0.067)$.

There were no significant differences of age, daily alcohol intake (g/day), years of drinking, frequency of previous detoxifications and blood alcohol concentration $(\mathrm{mg} / \mathrm{dl})$ between seizure and nonseizure patients: age $(43.67 \pm 8.5$ vs. $43.63 \pm 9.3, \mathrm{t}=-0.025, \mathrm{p}=0.98)$, daily alcohol intake ( $275.3 \pm 178.6$ vs. $232.6 \pm 188.1, \mathrm{t}=-1.438$, $\mathrm{p}=0.154)$, years of drinking (18.1 \pm 9 vs. $18.3 \pm 11, \mathrm{t}=$ $0.156, \mathrm{p}=0.876)$, frequency of previous detoxifications $(14.4 \pm 22$ vs. $9.6 \pm 14, \mathrm{t}=-1.422, \mathrm{p}=0.160)$, blood alcohol concentration $(140.5 \pm 144$ vs. $127.8 \pm 104, \mathrm{t}=$ $-0.576, \mathrm{p}=0.566)$.
Table 1. Demographic characteristics of the study population

\begin{tabular}{llc}
\hline & History of & Mean \pm SD \\
& AWs & \\
\hline Age & No & $43.63 \pm 8.27$ \\
& Yes & $43.67 \pm 8.45$ \\
\hline Years of drinking & No & $18.34 \pm 11.00$ \\
& Yes & $18.1 \pm 9.03$ \\
\hline Daily alcohol intake, g & No & $232.61 \pm 188.07$ \\
& Yes & $275.30 \pm 178.58$ \\
\hline Previous alcohol & No & $0.00 \pm 0.00$ \\
withdrawal seizures & Yes & $2.57 \pm 2.84$ \\
\hline Frequency of & No & $9.57 \pm 14.34$ \\
previous detoxifications & Yes & $14.35 \pm 22.34$ \\
\hline Blood alcohol & No & $127.79 \pm 103.97$ \\
concentration, mg/dl & Yes & $140.49 \pm 144.18$ \\
\hline CDT day 0 & No & $5.36 \pm 3.32$ \\
& Yes & $6.71 \pm 4.19$ \\
\hline HCT day 0 & No & $19.53 \pm 9.97$ \\
\hline Prolactin & Yes & $32.56 \pm 26.20$ \\
\hline & No & $13.09 \pm 7.61$ \\
& Yes & $16.79 \pm 11.46$ \\
\hline & & \\
& &
\end{tabular}

In the logistic regression model only $\mathrm{HCT}$ and $\mathrm{CDT}$ had a predictive property for a history of seizures $\left(\mathrm{R}^{2}=\right.$ $0.178 ;$ PRL: $B=0.028, p=0.203 ;$ HCT: $B=0.041, p=0.004$; CDT: $\mathrm{B}=0.088, \mathrm{p}=0.094)$. Therefore, only HCT and CDT were included in further analyses.

For \%CDT the best cutoff value was calculated at 3.75\%. For HCT the previously published cutoff value fixed at $23.9 \mu \mathrm{mol} / \mathrm{l}$ was used [9]. At the cutoff value of $3.75 \%$, $\%$ CDT showed a high sensitivity (76.5\%), and a lower specificity (44.2\%). HCT (cutoff value: $23.9 \mu \mathrm{mol} / \mathrm{l}$ ) reached a low sensitivity (56.9\%), but a higher specificity (78.3\%). The combination of HCT and \%CDT led to an increased specificity (88.4\%), while sensitivity persisted at a low level (47.1\%). The best predictive quality was calculated for the combined assessment of HCT and \%CDT (PPV $=0.504$, NPV $=0.870$ ). NPV diversified between $83.9 \%$ and $91.7 \%$. We found a higher sensitivity for the assessments '\%CDT $\geq 3.75 \%$,' 'HCT $\geq 23 \mu \mathrm{mol} / \mathrm{l}$ ', 'HCT $\geq 23 \mu \mathrm{mol} / \mathrm{l}$ or $\% \mathrm{CDT}$ $\geq 3.75 \%$ ' and 'HCT $\geq 23 \mu \mathrm{mol} / \mathrm{l}$ and $\% \mathrm{CDT} \geq 3.75 \%$ ' in men, while a lower specificity than women except for the assessment ' $\mathrm{HCT} \geq 23 \mu \mathrm{mol} / \mathrm{l}$ '. Other relevant gender differences were not found (table 2). Multinomial logistic regression models did not show a significant interaction between each variable tested and gender (data not shown). 
Table 2. Measures of the effectiveness of HCT (cutoff value $23.9 \mu \mathrm{mol} / \mathrm{l}$ ), CDT (cutoff value $3.75 \%$ ) and the combination of both parameters

\begin{tabular}{|c|c|c|c|c|c|c|c|}
\hline & Sensitivity (CI) & Specificity (CI) & PPV & NPV & $\operatorname{LR}(+)$ & PPV (0.03) & NPV $(0.03)$ \\
\hline \multicolumn{8}{|c|}{$\mathrm{HCT} \geq 23 \mu \mathrm{mol} / 1$} \\
\hline All & $56.9(42.2-70.7)$ & $78.3(70.4-84.8)$ & 39.5 & 87.9 & 2.62 & 7.5 & 98.3 \\
\hline Female & $42.9(9.9-81.6)$ & $75.9(56.5-89.7)$ & 30.7 & 84.2 & 1.78 & 5.2 & 97.7 \\
\hline Male & $59.1(43.2-73.7)$ & $78.9(70.0-86.1)$ & 41.2 & 88.5 & 2.80 & 8.0 & 98.4 \\
\hline \multicolumn{8}{|c|}{$\mathrm{CDT} \geq 3.75 \%$} \\
\hline All & $76.5(62.5-87.2)$ & $44.2(35.8-52.9)$ & 25.5 & 88.3 & 1.37 & 4.1 & 98.4 \\
\hline Female & $57.1(18.4-90.1)$ & $62.1(42.3-79.3)$ & 27.4 & 85.3 & 1.51 & 4.5 & 97.9 \\
\hline Male & $79.5(64.7-90.2)$ & $39.4(30.2-49.3)$ & 24.7 & 88.5 & 1.31 & 3.9 & 98.4 \\
\hline \multicolumn{8}{|c|}{$\mathrm{HCT} \geq 23 \mu \mathrm{mol} / \mathrm{l}$ or $\mathrm{CDT} \geq 3.75 \%$} \\
\hline All & $86.3(76.6-95.9)$ & $34.1(26.0-42.1)$ & 24.7 & 90.0 & 1.31 & 3.9 & 98.9 \\
\hline Female & $71.4(29.0-96.3)$ & $44.8(26.4-64.3)$ & 24.5 & 86.3 & 1.29 & 3.8 & 98.1 \\
\hline Male & $88.6(75.4-96.2)$ & $31.2(22.7-40.8)$ & 24.4 & 91.7 & 1.29 & 3.8 & 98.9 \\
\hline \multicolumn{8}{|c|}{$\mathrm{HCT} \geq 23 \mu \mathrm{mol} / \mathrm{l}$ and $\mathrm{CDT} \geq 3.75 \%$} \\
\hline All & $47.1(32.9-61.5)$ & $88.4(81.9-93.2)$ & 50.4 & 87.0 & 4.06 & 11.2 & 98.2 \\
\hline Female & $28.6(3.7-71.0)$ & $93.1(77.2-99.2)$ & 50.9 & 83.9 & 4.14 & 11.4 & 97.7 \\
\hline Male & $50.0(34.6-65.4)$ & $87.2(79.4-92.8)$ & 49.3 & 87.5 & 3.89 & 10.8 & 98.3 \\
\hline
\end{tabular}

PPV (0.03) = PPV assessed by using 3\% prevalence for alcohol withdrawal seizures, NPV (0.03) = NPV assessed by using $3 \%$ prevalence for alcohol withdrawal seizures.

Table 3. ROC curve analysis

\begin{tabular}{lllll}
\hline & & AUC & SE & CI \\
\hline CDT & All & 0.61 & 0.044 & $0.52-0.70$ \\
& Female & 0.68 & 0.107 & $0.48-0.89$ \\
& Male & 0.59 & 0.050 & $0.49-0.69$ \\
\hline HCT & All & 0.66 & 0.051 & $0.56-0.76$ \\
& Female & 0.60 & 0.153 & $0.30-0.90$ \\
& Male & 0.66 & 0.056 & $0.59-0.79$ \\
\hline HCT+CDT & All & 0.69 & 0.045 & $0.60-0.78$ \\
& Female & 0.73 & 0.126 & $0.48-0.98$ \\
& Male & 0.69 & 0.049 & $0.59-0.79$ \\
\hline
\end{tabular}

As we used the prevalence of AWS observed in a more general population of alcohol-dependent adults (3\% according to Le Strat et al. [26]), the estimated PPV were very low, whereas the NPV diversified between 97.7 and 98.9\% (table 2).

ROC curves showed a significant dominance for the combined assessment of HCT and \%CDT $($ AUC $=0.69)$ versus $\% \mathrm{CDT}$ alone $(\mathrm{AUC}=0.61, \mathrm{p}=0.03)$. There was also a difference between HCT and \%CDT combined (AUC = $0.69)$ versus $\mathrm{HCT}$ alone $(\mathrm{AUC}=0.66)$, although this was not significant $(\mathrm{p}=0.40)$ (tables 3,4$)$.
Table 4. Comparison of ROC curve analysis

\begin{tabular}{lllll}
\hline Contrast & $\begin{array}{l}\text { Differ- } \\
\text { ence }\end{array}$ & SE & CI & $\mathrm{p}$ \\
\hline All patients & & & & \\
$\quad$ CDT vs. HCT & -0.05 & 0.068 & -0.18 to 0.09 & 0.5007 \\
CDT vs. HCT+CDT & -0.08 & 0.038 & -0.16 to -0.01 & 0.0302 \\
HCT vs. HCT+CDT & -0.04 & 0.044 & -0.12 to 0.05 & 0.4002 \\
Female & & & & \\
HCT vs. CDT & -0.08 & 0.198 & -0.47 to 0.30 & 0.6716 \\
CDT vs. HCT+CDT & -0.04 & 0.112 & -0.26 to 0.18 & 0.6931 \\
HCT vs. HCT+CDT & -0.13 & 0.137 & -0.40 to 0.14 & 0.3493 \\
Male & & & & \\
HCT vs. CDT & 0.07 & 0.075 & -0.07 to 0.22 & 0.3351 \\
CDT vs. HCT+CDT & -0.10 & 0.040 & -0.18 to -0.02 & 0.0121 \\
HCT vs. HCT+CDT & -0.03 & 0.048 & -0.12 to 0.06 & 0.5471 \\
\hline
\end{tabular}

\section{Discussion}

The aim of the study was to analyze possible predictive qualities of HCT, CDT and PRL regarding AWS in order to optimize the assessment of the individual risk of AWS in a retrospective analysis.

For \%CDT we found the best cutoff value at 3.75\% (sensitivity $76.5 \%$, specificity $44.2 \%$ ). This result is not in concordance with the result of a previous study that cal- 
culated a best \%CDT cutoff value at 5.4\% (sensitivity 39\%, specificity $88 \%$ ) for alcohol-related seizures [11]. The authors of this investigation assert that \%CDT only is unsuitable for use as a predictive marker for AWS. PRL showed no relevant predictive qualities and was therefore omitted in the further statistical analysis.

The correlation between HCT levels and the risk of first-onset alcohol withdrawal seizures has been described in several investigations $[6,7,9,27]$. How HCT induces AWS is not exactly revealed. Hyperhomocysteinemia leads to an upregulation of the NMDA receptor system. Ethanol acts as an antagonist of the NMDA receptors. One current hypothesis for the genesis of AWS is that during detoxification amino acids like glutamate and HCT lead to overstimulation of the NMDA receptors, but on the other hand the antagonistic effect of ethanol decreases $[5,28]$. Investigations showed decreasing plasma HCT levels during alcohol detoxification to normal levels several days after alcohol abstinence was achieved $[5-7,29]$. The convulsant action of HCT is also shown in experimental animal studies. For example, HCT infusions generated tonic-clonic seizures in rats [30]. In other investigations it is shown that NMDA and non-NMDA antagonists have a protective effect against HCT-induced seizures [31, 32].

In our study best values were found for the combined assessment of HCT at a cutoff value of $23.9 \mu \mathrm{mol} / \mathrm{l}$ and $\% \mathrm{CDT}$ at a cutoff value of $3.75 \%$ (sensitivity $47.1 \%$, specificity $88.4 \%$ ). In that case the PPV is $50.4 \%$, so for those patients the risk of suffering an AWS is fairly high. Using the prevalence for AWS of a more general population leads to higher NPV. It is of note that our patient population was formed by severe alcohol-dependent patients, but the prevalence of 3\% according to Le Strat et al. [26] was assessed in a general alcohol-dependent population.
Therefore, the informative value of this result seems to be limited.

These results may be unsatisfactory for clinical use to predict AWS because of the high possibility of false-positive and false-negative findings. Identifying patients with a very low risk of AWS can represent a high importance in order to avoid subjecting these patients to unnecessary pharmaceutical therapy which can cause dangerous side effects. In this context the NPV attains more weight. Patients with a plasma HCT level below $23.9 \mu \mathrm{mol} / \mathrm{l}$ and \%CDT level below $3.75 \%$ have a low risk of developing an AWS (9.2\%). Particularly in patients above these cutoff values, a prophylactic medication with an antiepileptic drug should be taken into account.

In addition to HCT and \%CDT, it can be useful to include other markers for a better significance of appraising the risk of AWS. We made a retrospective analysis. Therefore, the interpretation of our results is limited and investigations of further biological markers of AWS, using a prospective design, are necessary in order to decrease type II error. In many studies ethyl glucuronide was discussed as a new marker of alcoholism, but a recent investigation showed no correlation between ethyl glucuronide and a history of seizures [33]. Recent reports assessed the predictive value of thrombocytes and HCT. Berggren et al. [34] showed a correlation between thrombocytopenia and the development of delirium tremens and seizures in alcohol withdrawal patients.

In conclusion, in spite of its retrospective nature, our investigation may support the hypothesis that assessing certain biomarkers in alcohol-dependent patients can be valuable in appraising the individual risk of AWS and in allowing individual therapy strategies. Further studies are necessary to increase the interpretability of our results.

\section{References}

1 Mezquita L, Stewart SH, Ibanez MI, Ruiperez MA, Villa H, Moya J, Ortet G: Drinking motives in clinical and general populations. Eur Addict Res 2011;17:250-261.

2 Rehm J, Patra J, Gnam WH, SarnocinskaHart A, Popova S: Avoidable cost of alcohol abuse in Canada. Eur Addict Res 2011;17:7279.

3 de Millas W, Ganzer F, Kuhn S, Haasen C: Oxazepam versus clomethiazol in alcohol withdrawal treatment. Eur Addict Res 2010; 16:179-184.
4 Bleich S, Carl M, Bayerlein K, Reulbach U, Biermann T, Hillemacher T, Bonsch D, Kornhuber J: Evidence of increased homocysteine levels in alcoholism: the Franconian alcoholism research studies (FARS). Alcohol Clin Exp Res 2005;29:334-336.

5 Bleich S, Degner D, Wiltfang J, Maler JM, Niedmann P, Cohrs S, Mangholz A, Porzig J, Sprung R, Ruther E, Kornhuber J: Elevated homocysteine levels in alcohol withdrawal. Alcohol Alcohol 2000;35:351-354.
6 Bleich S, Degner D, Bandelow B, von Ahsen N, Ruther E, Kornhuber J: Plasma homocysteine is a predictor of alcohol withdrawal seizures. Neuroreport 2000;11:2749-2752.

7 Bayerlein K, Hillemacher T, Reulbach U, Mugele B, Sperling W, Kornhuber J, Bleich S: Alcoholism-associated hyperhomocysteinemia and previous withdrawal seizures. Biol Psychiatry 2005;57:1590-1593.

8 Ubbink JB, Becker PJ, Vermaak WJ, Delport $\mathrm{R}$ : Results of B-vitamin supplementation study used in a prediction model to define a reference range for plasma homocysteine. Clin Chem 1995;41:1033-1037. 
9 Bleich S, Bayerlein K, Hillemacher T, Degner D, Kornhuber J, Frieling H: An assessment of the potential value of elevated homocysteine in predicting alcohol-withdrawal seizures. Epilepsia 2006;47:934-938.

10 Stibler H: Carbohydrate-deficient transferrin in serum: a new marker of potentially harmful alcohol consumption reviewed. Clin Chem 1991;37:2029-2037.

11 Brathen G, Bjerve KS, Brodtkorb E, Bovim G: Validity of carbohydrate deficient transferrin and other markers as diagnostic aids in the detection of alcohol related seizures. J Neurol Neurosurg Psychiatry 2000;68:342348

12 De A, Boyadjieva N, Oomizu S, Sarkar DK: Ethanol induces hyperprolactinemia by increasing prolactin release and lactotrope growth in female rats. Alcohol Clin Exp Res 2002;26:1420-1429.

13 Emanuele NV, Lapaglia N, Emanuele MA: Impact of acute and chronic ethanol exposure on prolactin in both male and female rats. Endocrine 2001;16:29-37.

14 Schuckit MA, Parker DC, Rossman LR: Ethanol-related prolactin responses and risk for alcoholism. Biol Psychiatry 1983;18:11531159.

15 Frias J, Rodriguez R, Torres JM, Ruiz E, Ortega E: Effects of acute alcohol intoxication on pituitary-gonadal axis hormones, pituitary-adrenal axis hormones, beta-endorphin and prolactin in human adolescents of both sexes. Life Sci 2000;67:1081-1086.

16 Kutscher S, Heise DJ, Banger M, Saller B, Michel MC, Gastpar M, Schedlowski M, Exton M: Concomitant endocrine and immune alterations during alcohol intoxication and acute withdrawal in alcohol-dependent subjects. Neuropsychobiology 2002;45:144-149.
17 Wilhelm J, Heberlein A, Karagulle D, Groschl M, Kornhuber J, Riera R, Frieling H, Bleich S, Hillemacher T: Prolactin serum levels during alcohol withdrawal are associated with the severity of alcohol dependence and withdrawal symptoms. Alcohol Clin Exp Res 2011;35:235-239.

18 Larson ER, Ariano MA: $\mathrm{D}_{3}$ and $\mathrm{D}_{2}$ dopamine receptors: visualization of cellular expression patterns in motor and limbic structures. Synapse 1995;20:325-337.

19 Durham RA, Eaton MJ, Moore KE, Lookingland KJ: Effects of selective activation of dopamine $\mathrm{D}_{2}$ and $\mathrm{D}_{3}$ receptors on prolactin secretion and the activity of tuberoinfundibular dopamine neurons. Eur J Pharmacol 1997;335:37-42.

20 Ben-Jonathan N, Hnasko R: Dopamine as a prolactin (PRL) inhibitor. Endocr Rev 2001; 22:724-763.

21 Gessa GL, Muntoni F, Collu M, Vargiu L, Mereu G: Low doses of ethanol activate dopaminergic neurons in the ventral tegmental area. Brain Res 1985;348:201-203.

22 Imperato A, Di Chiara G: Preferential stimulation of dopamine release in the nucleus accumbens of freely moving rats by ethanol. J Pharmacol Exp Ther 1986;239:219-228.

23 Hillemacher T, Bayerlein K, Frieling H, Wilhelm J, Ziegenbein M, Kornhuber J, Bleich S: Elevated prolactin serum levels and history of alcohol withdrawal seizures. J Psychiatr Res 2007;41:702-706.

24 Hillemacher T, Frieling H, Bayerlein K, Wilhelm J, Kornhuber J, Bleich S: Biological markers to predict previous alcohol withdrawal seizures: a risk assessment. J Neural Transm 2007;114:151-154.

25 Wilhelm J, Bayerlein K, Hillemacher T, Reulbach U, Frieling H, Kromolan B, Degner D, Kornhuber J, Bleich S: Short-term cognition deficits during early alcohol withdrawal are associated with elevated plasma homocysteine levels in patients with alcoholism. J Neural Transm 2006;113:357-363.
26 Le Strat Y, Ramoz N, Pickering P, Burger V, Boni C, Aubin HJ, Ades J, Batel P, Gorwood $\mathrm{P}$ : The $3^{\prime}$ part of the dopamine transporter gene DAT1/SLC6A3 is associated with withdrawal seizures in patients with alcohol dependence. Alcohol Clin Exp Res 2008;32: 27-35.

27 Kurth C, Wegerer V, Degner D, Sperling W, Kornhuber J, Paulus W, Bleich S: Risk assessment of alcohol withdrawal seizures with a Kohonen feature map. Neuroreport 2001;12: 1235-1238.

28 Hillemacher T, Reulbach U, Bayerlein K, Wilhelm J, Bonsch D, Sperling W, Kornhuber J, Bleich S: Plasma homocysteine concentrations do not influence craving in alcohol withdrawal. Alcohol 2004;34:211-215.

29 Hultberg B, Berglund M, Andersson A, Frank A: Elevated plasma homocysteine in alcoholics. Alcohol Clin Exp Res 1993;17: 687-689.

30 Kubova H, Folbergrova J, Mares P: Seizures induced by homocysteine in rats during ontogenesis. Epilepsia 1995;36:750-756.

31 Folbergrova J: Anticonvulsant action of both NMDA and non-NMDA receptor antagonists against seizures induced by homocysteine in immature rats. Exp Neurol 1997; 145: 442-450.

32 Folbergrova J, Haugvicova R, Mares P: Behavioral and metabolic changes in immature rats during seizures induced by homocysteic acid: the protective effect of NMDA and nonNMDA receptor antagonists. Exp Neurol 2000;161:336-345

33 Wurst FM, Seidl S, Ladewig D, Muller-Spahn F, Alt A: Ethyl glucuronide: on the time course of excretion in urine during detoxification. Addict Biol 2002;7:427-434.

34 Berggren U, Fahlke C, Berglund KJ, Blennow $\mathrm{K}$, Zetterberg H, Balldin J: Thrombocytopenia in early alcohol withdrawal is associated with development of delirium tremens or seizures. Alcohol Alcohol 2009;44:382-386. 